\title{
Temizlik Robotlarında Kullanılan Aparatların Müșteri Geri Bildirimlerine Göre Geliştirilmesi
}

\author{
Hakan MADEN ${ }^{1}$, Ömer Şaban KAMBER ${ }^{1}$ \\ 1İhlas Ev Aletleri İmalat ve Tic. A.Ş., 34524, İSTANBUL
}

(Alınış / Received: 11.03.2020, Kabul / Accepted: 01.07.2020)

\section{Anahtar Kelimeler \\ Endüstriyel Tasarım, Pencere, sert zemin ve parke marley tasarım, \\ Koltuk kanepe aparatı, \\ Dar köșe ve kenar aparatı,}

\begin{abstract}
Özet: Genellikle ev hanımları zamanlarının çoğunu evlerinde geçirmektedir. Ev hanımları genellikle temizlik, çamașır, bulașık, yemek, ütü gibi bir sürü işlerle uğraşmaktadır. Bu ișlerden en zor olanı genellikle camların, koltukların ve dar köșe kenarların temizlenmesidir. Müşteriler ile yapılan memnuniyet anketinde temizleme aparatların geliştirilmesi ortaya çıkmıştır. Bu amaçla, ev hanımların pencere, sert zemin/parke marleyleri, koltuk kanepe ve dar köșe ve kenarlarının temizleme işlerini kolaylaştırmak için aparat tasarımlarının geliştirilmesi karar verilmiștir. Pencere silme aparatı üç zeminde temizleme yapabilecek şekilde aparat tasarımı geliştirilmesi hedeflenmiştir. Bu aparat kullanılmak istenildiği zemine göre aparat üzerindeki yuvalara ilgili parçalar yerleștirilerek kullanılması düșünülmüștür. Bu parçaların montajı kolay olacak șekilde tasarımı yapılması hedeflenmiștir. Koltuk kanepe aparatı üzerinde bulunan firça parçasının kolay çıkartılması hedeflenmiştir. Dar köșe ve kenarların temizlenmesi özel aparat tasarımların yapılması hedeflenmiştir. Bu aparat mevcut yapıdaki işlevi yerine getirecek şekilde amaçlanmıștır. Yapılan bu aparat tasarım çalışmaları kullanılacak ürünle ve ürün çizgilerine göre aparat tasarım geliştirilmesi hedeflenmiştir.
\end{abstract}

\section{Improvement of Apparatus Used in Cleaning Robots According to Customer Feedback}

\section{Keywords}

Industrial design,

Window, hard floor and hardwood marley design, Seat sofa apparatus, Narrow corner and edge,

\begin{abstract}
Housewives often spend most of their time in their homes.Housewives are often involved in cleaning, laundry, dishwashing, cooking and ironing. The most difficult of these jobs is the cleaning of windows, seats and narrow corner edges. In the satisfaction survey conducted with customers, the development of cleaning apparatus has emerged. For this purpose, it was decided to develop apparatus designs for housewives to facilitate the cleaning work of windows, hard floor / parquet marbles, sofa couches and narrow corners and edges. It is aimed to develop apparatus design so that the window wiping apparatus can be cleaned on three floors. This apparatus is intended to be used by placing relevant parts in the slots on the apparatus according to the floor to be used. These parts are designed to be easy to assemble. It is aimed to remove the brush piece located on the seat couch apparatus easily. It is aimed to make special apparatus designs for cleaning narrow corners and edges. This apparatus is intended to perform the function of the present structure. This apparatus design work is aimed to develop apparatus design according to product and product lines to be used.
\end{abstract}

\section{Giriş}

Globalleșen ekonomi, şirketleri daha rekabetçi ve daha çevik şirketler olmaya zorlamaktadır. Globalleşmenin sonucunda ortaya çlkan müşteri isteklerinin farklılaşması, ürünlerin hayat

Doi: $10.35354 /$ tbed.538321 kısalması gibi olgular şirketlerin yeni ürün geliştirme konseptini tamamıla değiștirmiştir. Artık günümüzde yeni ürün geliștirme, maliyet ve zamanın içinde bulunduğu zor bir denklem haline dönüşmüștür. Nitekim endüstriyel ürün geliștirme, iș prosedürlerinin, değișen talepler doğrultusunda, sürekli iyileștirilmesini gerekli kılmaktadır. Ürünlerin sürekli yenilendiği ortamda tasarım ve yenilik 
konularına ilginin gittikçe artması da kaçınılmazdır. Ürün geliştirme sürecinin önemli bir alt süreci olarak kabul edilen tasarım, ürün yenileme sürecinin temel bir fonksiyonudur ve iş performansının ve rekabet edilebilirliğin gelişmesi için uygulanır. Tasarımın amacı sosyal, organizasyonel ve mühendislik yaklaşımını etkin bir şekilde gerçekleștirerek ürün ve hizmeti iyileştirmek veya yeniden oluşturmaktır [1]. Amerikan Endüstriyel Tasarımcılar Topluluğuna göre ise endüstriyel tasarım, kullanıcı ve üreticinin karşılıklı yararını gözeterek; ürünlerin işlev, fayda ve görünümünü optimize edecek șekilde yeni ürün fikirleri yaratmaya ve geliştirmeye yönelik profesyonel bir etkinliktir. Tasarım kavramının bu kadar önemli olması ürün tasarım yönetimi kavramını da beraberinde getirmektedir. Buna paralel, genelde ürün geliștirme sürecine, özelde ise ürün tasarımına destek teknik ve yaklaşımların işletmelerde önemleri ve uygulamaları giderek artmaktadır [2].

Tasarım işlemi çalışmalarında genellikle aşağıda bahsedilen temel bazı modeller önerilmektedir [3].

$$
\begin{array}{ll}
\checkmark & \text { Kuralcı Model, } \\
\checkmark & \text { Tanımsal Model, } \\
\checkmark & \text { Bilgisayara Dayalı Modeller. }
\end{array}
$$

Kuralcı modeller, 'doğru' bir tasarıma varmak için tasarım esnasında uyulan kurallı faaliyetlerdir. Kuralcı modeller, sistematik veya metodik tasarım yaklaşımları için temel teşkil eden modeller olarak gösterilir. Tasarım işleminde bu modellerin, aşağıda görülen birkaç temel aşamadan oluştuğu görülmektedir.
1. Problemin tarifi aşaması,
2. Kavramsal tasarım aşaması,
3. Şekillendirme aşaması,
4. Detaylı tasarım aşaması.

Problemin tarifi aşamasında, tasarım problemi belirtilir, ihtiyaçlar ve şartnameler meydana getirilir. Kavramsal tasarım aşamasında; fonksiyonlar, yerine getirilmek için ayrılır. Fonksiyonlar olabildiğince alt fonksiyonlarına ayrıştırılmaya çalışılır. Bundan sonra, iş yeri imalat şartları da göz önünde bulundurularak ürün çalışma prensipleri belirlenir.

Uygun çalışma prensipleri belirlendikten sonra, şekillendirme tasarımına başlanır. Şekillendirme tasarımı esnasında, seçilen çalışma prensiplerini gerçekleştirebilecek mekanik parçalar tasarlanır ve bu parçalar arası sıralı ilişkiler belirlenir. Şekillendirme tasarımı bittikten sonra, her bir bağımsız parçanın ayrıntılı tasarımı başlayabilir. $\mathrm{Bu}$ tasarım aşaması esnasında, her bir parça eksiksiz şekilde detaylandırılarak, ölçü, tolerans ve malzeme özellikleri belirlenir.

Ürün tasarımı ve ürün geliştirme, kullanıcı gereksinimlerini ve endüstrinin gereksinimlerini karşılayan disiplinler arası bir etkinlik olmaktadır [4].
Endüstriyel ürünlerin tasarımı yeni ürün geliştirme kapsamında ele alınır [5].

Ürün geliştirme aşamaları, birçok karar noktalarını içermektedir. Hata içeren bir tasarım kavramı nadiren daha sonraki aşamalarında telafi edilebilir. Bu nedenle en kritik karar noktalarını yönetmek için tasarım kavramları başlangıçta değerlendirilmelidir. $\mathrm{Bu}$ değerlendirme, tasarım ilk aşamalarında uygulandığında ürün geliştirme maliyetinin \%70'e kadar azaltmaktadır. Başarılı bir tasarım kavramı, piyasa için farklı, başarılı ve yenilikçi olmalıdır [6,7].

Kavramsal tasarım konusuyla ilgili olarak pek çok farklı alanda çalışmalar yapılmaktadır. Yapılan bu çalışmalar içerisinde, mekanik sistemlerin kavramsal tasarımı için sistem yapısının metodolojisinin belirlenmesi en az üzerinde inceleme yapılan bir konudur [8].

$\mathrm{Bu}$ çalışmada evlerde bayanların temizlenmekte zorlandığı cam, sert zemin ve parke parleylerin temizlenmesi için aparat tasarımı yapılması amaçlanmıştır. Tasarımı yapılacak aparatın üç farklı yüzeyi temizleme işini aynı aparatta olması için bütünleşik bir tasarım yapılması hedeflenmiștir.

\section{Tasarım Parametrelerin Belirlenmesi}

Pazar araștırmaları ve teknolojik gelișmelerden dolayı yeni bir aparat tasarımı ihtiyacı oluşmuştur. Bu yapılacak olan yeni aparat tasarımda müşterinin beklentileri ve isteklerini ölçmek için telefon yoluyla sözlü anketler yapılmıştır. Bu ankette daha önce "Cleanmax" temizlik robotu cihazını ürünü satın alan müșteriler ile yapılmıștır. 327406 müșteri ile yapılan sözlü ankette aşağıdaki sorular sorulmuştur.

1. Cleanmax temizlik robotunda hangi aparatın olmasını isterdiniz?

2. İstemiş olduğunuz aparat yapılırsa ürün

\begin{tabular}{|c|c|c|}
\hline \multicolumn{3}{|c|}{$\begin{array}{l}\text { Yeni Cleanmax cihazında hangi aparatın olmasını } \\
\text { isterdiniz? }\end{array}$} \\
\hline Adet & Müşteri İstekleri & İstek Adetleri \\
\hline 1 & Cam silme için bir aparat olsa, & 281547 \\
\hline 2 & $\begin{array}{l}\text { Sert zeminlerin temizlenmesinde } \\
\text { kolay temizleyen aparat olsa, }\end{array}$ & 264124 \\
\hline 3 & $\begin{array}{l}\text { Parke marleylerin kolay } \\
\text { temizlemesi için aparat olsa, }\end{array}$ & 248653 \\
\hline 4 & $\begin{array}{l}\text { Dar yüzeylerin temizlenmesi için } \\
\text { aparat olsa, }\end{array}$ & 238489 \\
\hline 5 & $\begin{array}{l}\text { Koltuk kanepe aparatında fırça } \\
\text { çlkartılabilir olması }\end{array}$ & 223917 \\
\hline 6 & $\begin{array}{l}\text { Koltuk altlarına kolay girebilecek } \\
\text { günlük süpürge aparat olsa, }\end{array}$ & 210428 \\
\hline 7 & $\begin{array}{l}\text { Perdelerin kolay temizlenmesi için } \\
\text { aparat olsa, }\end{array}$ & 132894 \\
\hline 8 & $\begin{array}{l}\text { Buhar ile temizleme yapan bir } \\
\text { aparat olsa, }\end{array}$ & 108265 \\
\hline 9 & $\begin{array}{l}\text { Dairesel dönen bir temizlik bir } \\
\text { aparat olsa, }\end{array}$ & 90526 \\
\hline
\end{tabular}
değiştirir misiniz?

Tablo 1. Cleanmax temizlik robotu cihaz istek özellikler 
Yukarıdaki tabloda en çok talep edilen 9 farklı aparat isteklerin oranları verilmiştir. Bu oranları yeni aparat tasarımda dikkate alınarak aparat tasarımı gerçekleştirmeye çalışılacaktır. 9 farklı aparat isteklerin ışındaki isteklerin adet sayıları düşük olduğundan yukarıdaki tabloda yer almamıştır. Yapılacak olan aparat tasarım çalışmasında dikkate alınmayabilir.

Tablo 2. Cleanmax temizlik robotu cihaz değişim oranları İstemiş olduğunuz özellikleri taşıyan yeni ürün temizlik robotu cihazını değiștirir misiniz?

\begin{tabular}{cc}
\hline Evet & 238152 \\
Hayır & 89254 \\
\hline
\end{tabular}

Yukarıdaki tablolardan anlaşılacağı gibi müşteri istemiş olduğu aparat geliştirildiğinde ürün değişimi \%72,2 oranındadır. $\mathrm{Bu}$ isteklerden ilk 6 maddesi üzerinde tasarım çalışmaları yapılacaktır. Bu amaçla farklı yeni bir aparat tasarımı yapılması karar verilmiştir.

\section{Cam Silme, Parke Marley ve Sert Zemin Aparatın Geliştirilmesi}

Tasarımı geliştirilecek aparat ile ilgili olarak;

$\checkmark \quad$ Cam silme olarak kullanılması

$\checkmark$ Sert zeminlerin temizlenmesinde kullanılması

$\checkmark \quad$ Parke marleylerin temizlenmesinde kullanılması

$\checkmark$ Mevcut ürün konseptine uygun tasarıma sahip olması için bütün bu özellikleri taşıyan compact bir aparat tasarımı yapılacaktır.

Aparat parçasının tasarım yapılmadan önce temizlik yapılan alanların incelenip ona göre endüstriyel tasarımlarının ortaya konulması gerekmektedir. $\mathrm{Bu}$ amaçla şekil 1'de görüldüğü gibi 3 farklı yüzeyin resimleri görülmektedir.

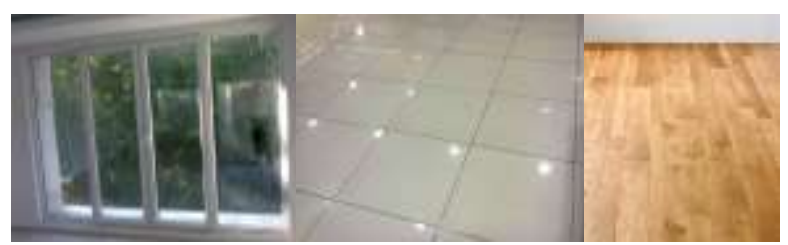

Şekil 1. Temizleme yapılan yüzeyler $[9,10,11]$

Pencerelerin temizliği incelendiğinde dik konumda olan yüzeyin temizlenmesini kolaylaştırmalıdır. Sert zemin yüzeyleri incelendiğinde derz aralarına giren kirlerin çıkartılmasını sağlayacak şekilde olması gerekiyor. Parke marleyli alanlarda yüzeylere zarar vermeyecek (çizik oluşumu) şekilde olmalıdır.

\subsection{Camların Temizlenmesi için Aparat Tasarımı}

Genel olarak piyasada sadece cam temizleme olarak birçok farklı aparatlar bulunmaktadır. Şekil 2'de piyasa bulunan cam temizleme aparatları resimleri bulunmaktadır.

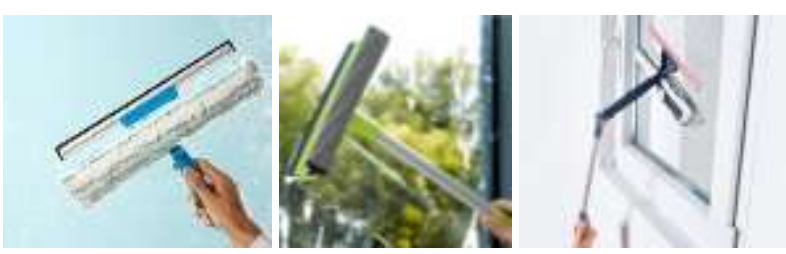

Şekil 2. Piyasadaki cam temizleme araçları $[14,15,16]$

Piyasada bulunan cam temizleme aparatları incelenmiştir. Yapılan incelemeler sonucunda yapılacak aparat tasarımında bez yapılı bir diğer tarafta yüzeyde kalan suyu alınması için bir yuvanın yapılması gerekmektedir.

Bu kriterlere göre ürünün ilke önce kabuk tasarımları yapılmıştır. Yapılan tasarımın resmi şekil 3'de görülmektedir. Şekil 3'de görülen cam silme aparat tasarımında alt kısmında camdaki kirleri temizlemek için sünger konumlandırılmıştır. Ön tarafında ise camdaki suyun emilmesi emiş ağzı yapılmıștır. Cihazın teleskobik boru üzerinde su fiskiyesi ile temizlenecek yüzeye kimyasal temizleme suyu atmaktadır.

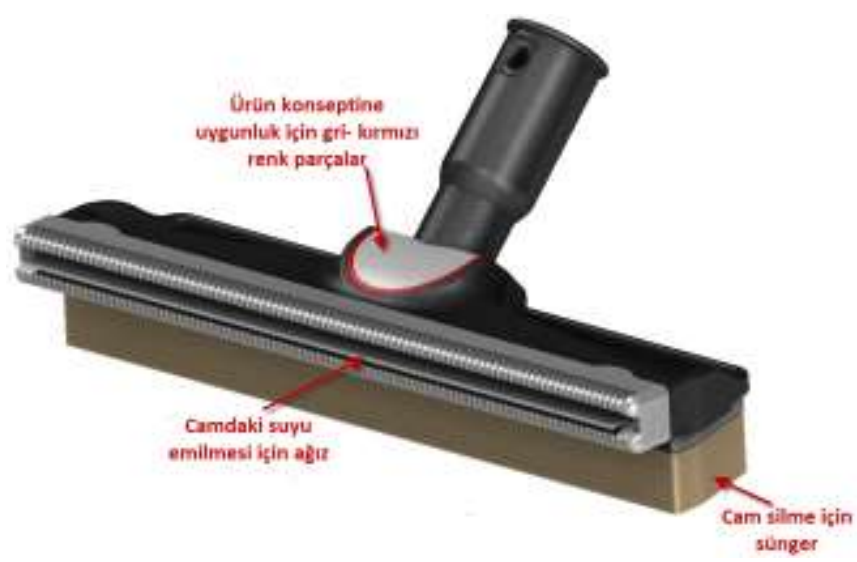

Şekil 3. Cam temizleme aparatı

Şekil 4'te cam temizleme süngeri görülmektedir. Sünger alttaki plastiğe özel yapıştırıcılar ile yapıștırılacaktır. Bu yapıştırıcı suya ve kimyasal temizleme maddelere karşı dayanıklı olacak şekilde seçilmiştir. Camdaki kimyasal temizleme suyunu temizleme süngeri ile yüzeyde kirin temizlenmesi sağlanır.

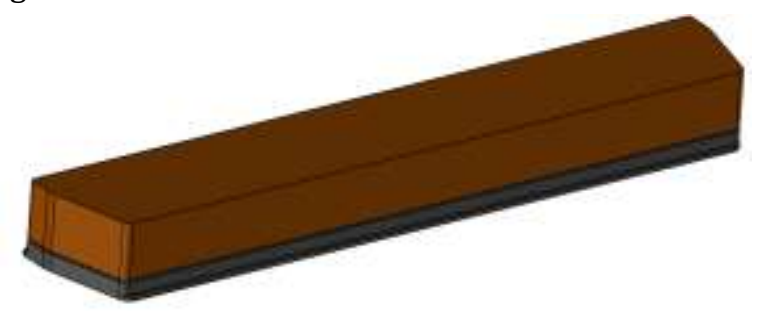

Şekil 4. Cam temizleme süngeri

Şekil 5'te camın silinmesinden sonra yüzeyde kalan suyun emilmesiniz sağlayan silikon malzemeden üretilmiş parça görülmektedir. Parça incelendiğinde orta kısmında dışarıya çıkan bir yapı vardır. Bu yapı cam yüzeyinde gezdirildiğinde camdaki suyu toplamaktadır. Yapının altında ve üstündeki boşluklardan temizlik robotu ile suyu emerek camın temizlenmesi sağlanır. Esnek yapının altındaki su emiş 
yerlerinin üstündeki emiş yerlerinin göre daha az olduğu görülmektedir. Bunun nedeni emiş ağzı cama temas ettiğinde emiş yerlerinin çok olan kısım alt tarafta kalmaktadır. Uç kısım cam yüzeyde gezdiğinden altta toplanan kirli su hızlı bir şekilde aşağıya ineceğinden dolayı halıya veya diğer yüzeyleri kirletmemesi için alt tarafta emiş yerleri artırllarak kirli suyun hızlı bir șekilde emilmesini sağlamaktadır.

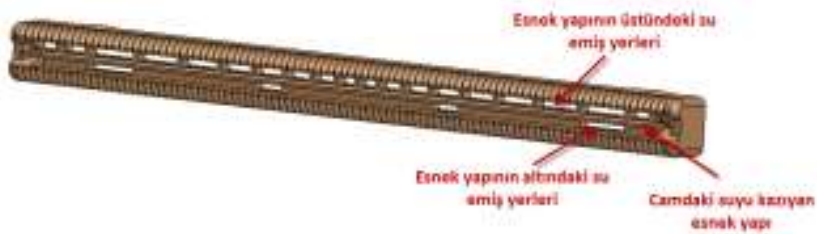

Şekil 5. Cam suyu emilmesini sağlayan uç yapı Cam silme aparatının dış kabuk tasarımı mevcut kullanılacak ürünün konsept tasarımına uygun olmasını gerekmektedir. Bu kriterlere göre cam silme aparatının tasarımı yapılmıştır. Yapılan tasarım şekil 6'da görülmektedir.

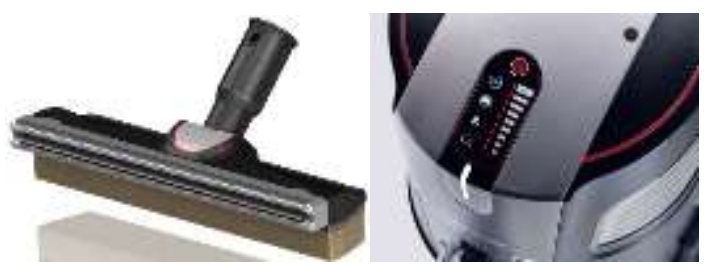

Şekil 6. Cam silme aparatının mevcut cihazı uygun konsept tasarımı

\subsection{Sert Zeminleri Temizlemek için Aparat Tasarımı}

Genel olarak piyasada sert temizlemek için birçok farklı aparatlar bulunmaktadır. Şekil 7'de piyasa bulunan sert zemin temizleme aparatları resimleri bulunmaktadır.

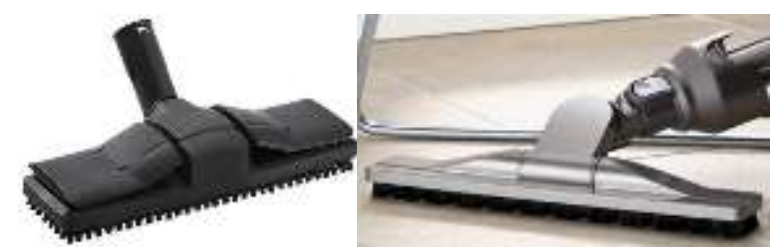

Şekil 7. Piyasadaki sert zemin temizleme araçları $[12,13]$

Piyasada bulunan sert zemin temizleme aparatları incelenmiştir. Yapılan incelemeler sonucunda yapılacak aparat tasarımında alt yüzeyinde sert kılların olması gerektiği görülmüştür. Piyasadaki ürünlere bakıldığından sadece sert zemin üzerinde kuru halde temizlenmesini sağlamaktadır. Şekil 8'de görülen cam silme aparat tasarımında alt kısmında sert zeminleri temizlemek için sert kıllar olan parça görülmektedir. Bizim geliştirdiğimiz aparatta sert zeminleri islak olarak temizleme yapmaktadır. Cihazın teleskobik boru üzerinde su fiskiyesi ile temizlenecek yüzeye kimyasal temizleme suyu atmaktadır.

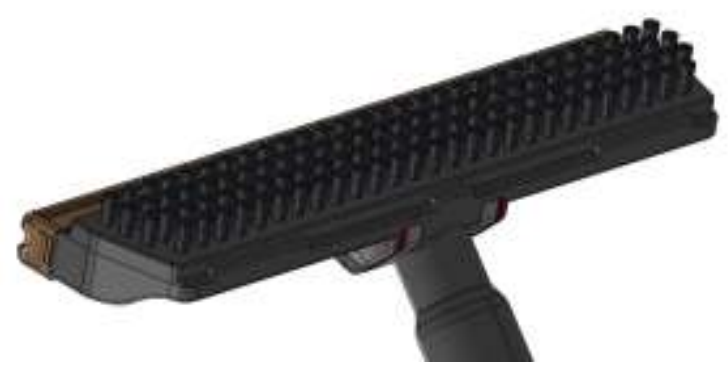

Şekil 8. Sert zemin temizleme aparatı

Şekil 9'de sert zemin temizleme alt parçası görülmektedir. Bu parça yüzeyinde toplam 114 adet sert kıl yuvası bulunmaktadır. Bu kılların özelliği PA66 malzemede kıl kalınlığ 0,35 mm ve her bir yuvada 80 adet kıl olarak belirlenmiştir.

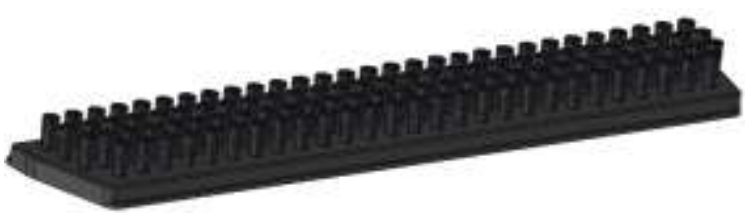

Şekil 9. Sert zemin alt parçası

Sert zemin üzerinde atılan kimyasal temizleme su ile alt taraftaki sert kıllar vasıtasıyla sert yüzeydeki kirlerin çıkartılmasını sağlamaktadır. Aparat döndürülerek ön tarafta bulanan emiş ağzı ile kirli su cihaz içerisine çekilmesi sağlanır. Bu şekilde sert zeminlerin temizlenmesi sağlanır.

\subsection{Parke Marleylerin Temizlenmesi için Aparat Tasarımı}

Genel olarak piyasada parke marleylerin temizlenmesi için birçok farklı aparatlar bulunmaktadır. Şekil 10'de piyasa bulunan cam temizleme aparatları resimleri bulunmaktadir.

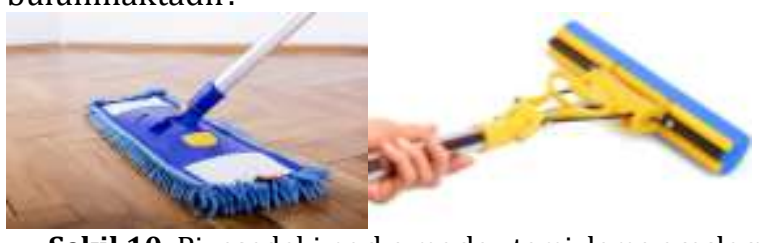

Şekil 10. Piyasadaki parke marley temizleme araçları $[10,11]$

Piyasada bulunan parke marley temizleme aparatları incelenmiştir. Yapılan incelemeler sonucunda yapılacak aparat tasarımında alt yüzeyinin yumuşak yapıda olması gerektiği görülmüştür. Piyasadaki ürünlere bakıldığından sadece parke marley zemin üzerinde yarı sslak halde temizlenmesini sağlamaktadır. Yumuşak yüzeyde kaba kirleri almaktadır. Yüzeyde hala ıslaklık kalmakta yüzey kuruduğunda yüzeyde kirlilikler olmaktadır. Şekil 11 'de görülen parke marley tasarımında alt kısmında parke marley temizlemek için yumuşak yapıda (Poliüretan malzemeden) olan parça görülmektedir. Yumuşak yapı sayesinde yüzeyi temizlemekte, aparat ters çevrilerek yüzeyde kalan kirli suyu temizlenmesi sağlanmaktadır. $\mathrm{Bu}$ sayede yüzeyde kirli su 
kalmamakta hem yumuşak yüzey olduğunda parke marley yüzeyleri çizmemektedir.

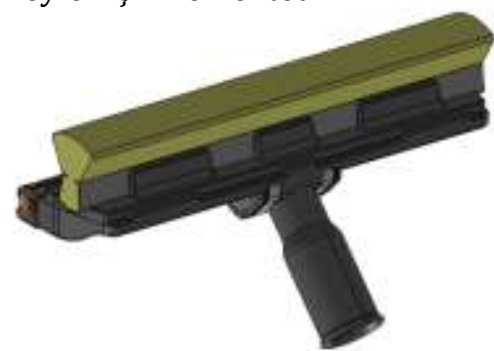

Șekil 11. Sert zemin temizleme aparatı

Şekil 12'de parke marley temizleme alt parçası görülmektedir. Parke marley temizleme grubu toplam 3 parçadan oluşmaktadır. Bunlar poliüretan özel sünger, süngerin montaj edildiği metal parça ve bunların montaj edildiği plastik taşıyıcı plastikten oluşmaktadır.

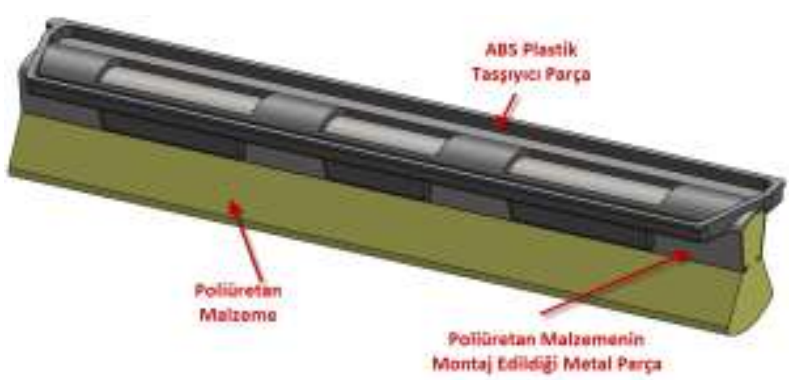

Şekil 12. Parke marley yüzey temizleme aparatı

\section{4. Üç Farklı Yüzey Temizlemenin Tek Aparatta Kullanılması}

Pencere, sert zemin ve parke marley yüzeylerin temizlenmesi için aparat tasarımları yapılmıștır. Yapılan bu tasarımların resimleri şekil 13'te görülmektedir. Bu tasarımlar tek bir aparat üzerinde temizlik yapılacak yüzeye göre aparata takılması gerekmektedir.

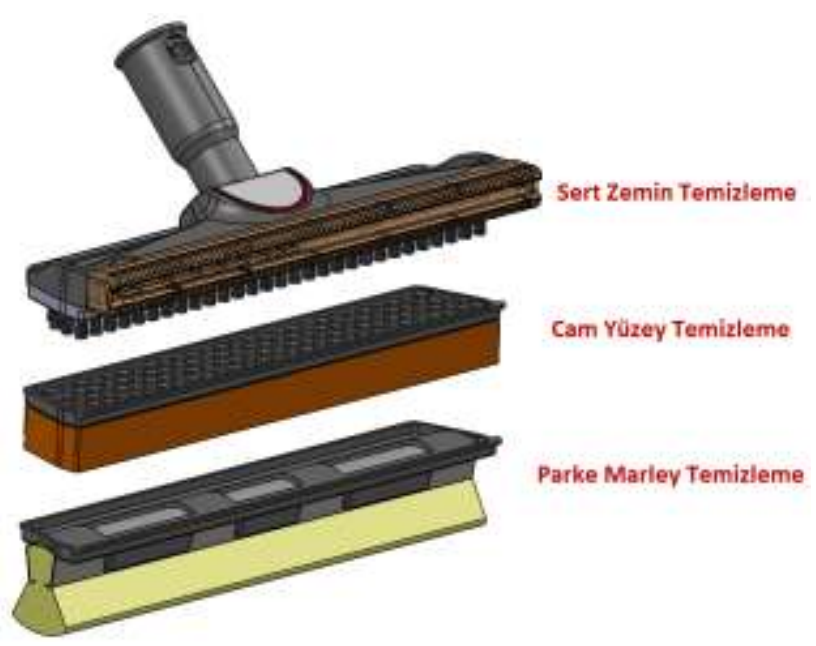

Şekil 13. Aparat tasarımlarının görünüşü

Aparat üzerine montaj edilmiş temizleme aparatları çıkartılması kolay olması için yanda bulunan çıkıntı vurulduğunda yuvasından çlkmaktadır. Temizleme aparatının çıkartma yeri şekil 14'te görülmektedir.

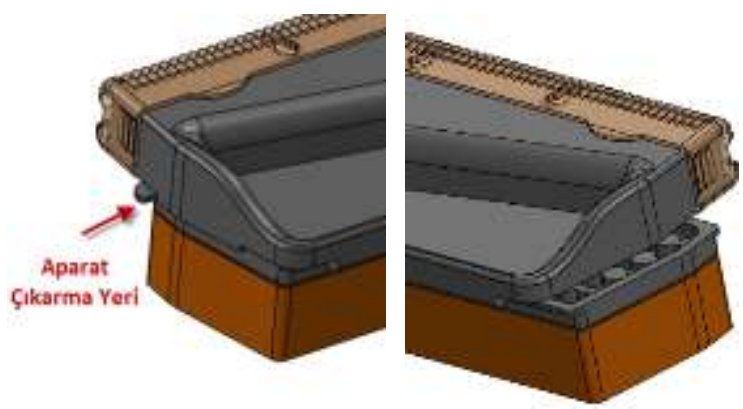

Şekil 14. Temizleme aparatlarının çıkartma yeri

Aparat üzerine montaj edilmiş temizleme aparatları çıkartılırken veya takılırken aparatın altında bulunan kızaklara takılmaktadır. Bu kızaklar şekil 15'te görülmektedir.

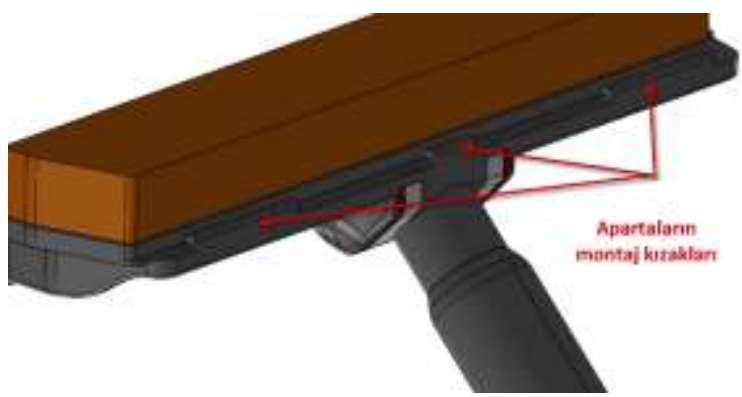

Şekil 15. Temizleme aparatlarının takılması ve çıkartılmasında kullanılan kızaklar

\section{Koltuk Kanepe Aparatı Geliştirilmesi}

Tasarımı geliştirilecek aparat ile ilgili olarak;

$\checkmark \quad$ Koltuk kanepede bulunan sabit firçanın kolay çlkartılabilir olması

$\checkmark$ Koltuk kanepede emiş vakum değerinin düşüş olmaması

$\checkmark$ Mevcut tasarıma uygun çıkartılabilir firça tasarımı ve yeni bir koltuk kanepe tasarımı

Mevcut ürün ile birlikte koltuk kanepe aparatı verilmektedir. $\mathrm{Bu}$ aparat şekil 14'te görülmektedir. Ürün satışı sonrası müșterilerle yapılan sözlü mülakat sonrası bu aparatın geliştirilmesi gerekliliği ortaya çıkmıştır.

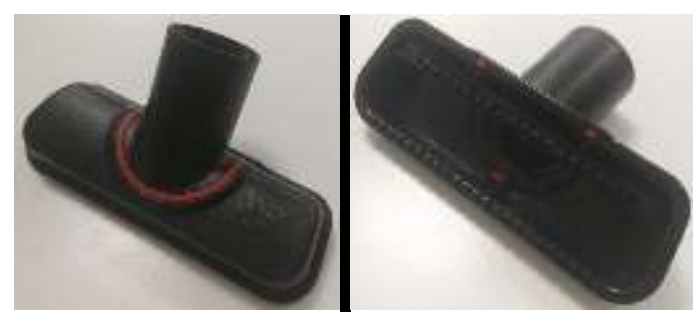

Şekil 14. Koltuk kanepe aparatı

$\mathrm{Bu}$ amaçla müşterilerle tekrar iletişime geçilerek ne tür problemler neden olduğu konusu hakkında bilgiler alındı. Müşterilerden alınan bilgiler koltuk kumaşları hassas olan koltuklarda aparat üzerinde bulunan kılların zarar verdiğini söylemişlerdir. Koltuk kanepe aparatında ya kıl grubunun çıkartılabilir veya daha 
yumuşak kıl yapısı ile kumaşa zarar vermeyecek şekilde olmasını istediklerini dile getirdiler.

\subsection{Mevcut Koltuk Aparatının Yumuşak Kıl Olarak İmal Edilmesi}

Mevcut koltuk kanepe aparatında kıllar PA66 hammadde ve kalınlığı $0,2 \mathrm{~mm}$ olarak kullanılmaktadır. Şekil 15'te mevcut koltuk kanepe aparatının kıl grubu görülmektedir.

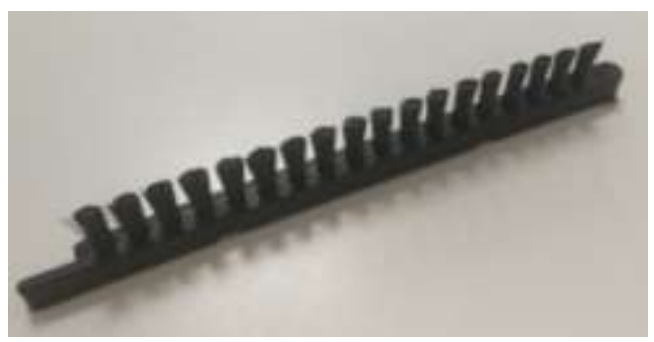

Şekil 15. Koltuk kanepe aparatı kıl grubu

Koltuk kanepe aparatındaki kılları yumuşak yapmak için kıl kalınlığı azaltılması gerekmektedir. Hassas koltuk kumaşlarına zarar vermemesi kıl kalınlığı 0,05 mm olması gerekmektedir. Bu kalınlıkta kıl seçimi yapıldığında koltuklara zarar vermeyecektir fakat ürün kılları kısa zamanda deforme olacaktır. Örnek olarak şekil 16 deforme olmuş 0,12mm kalınlığındaki kıl yapısı görülmektedir. $\mathrm{Bu}$ da ileride müşteri memnuniyetsizliğine neden olacaktır. Ayrıca koltuk üzerine yapılacak temizleme ișleminde kir ve tozun çıkartılması zor olacaktır. Bu nedenlerden dolayı kıl kalınlıkların azaltılması vazgeçilmiştir.

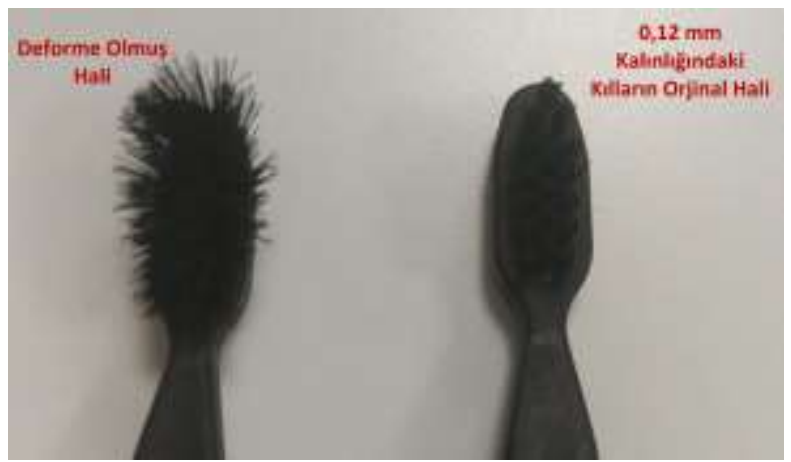

Şekil 16. Deforme olmuș kıllar

\subsection{Mevcut Koltuk Aparatının Emiş Vakum Değeri}

Mevcut koltuk kanepe aparatının yumuşak kılların yapılması düșünülmemesinden dolayı aparatta kılların çıkartılabilir olması amacıyla tasarım yapılmasına karar verilmiştir. Tasarım aşamasına geçilmeden önce mevcut koltuk kanepe aparatının emiş vakum değerinin bilinmesi gerekmektedir. Yapılacak tasarımın emiş vakum değerinde düşüşe neden olması istenmektedir.

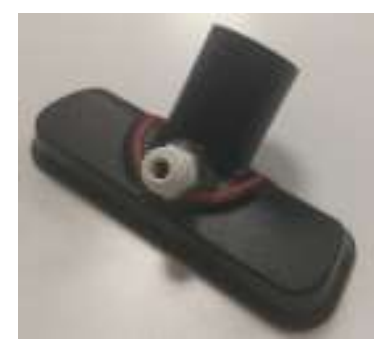

Şekil 17. Mevcut koltuk kanepe aparatının emiş vakum ölçümü

Şekil 17'de görüldüğü gibi mevcut koltuk kanepe aparatının vakum değerinin ölçülmesi için ölçüm aparatı montajı yapılmıştır. Aparatın kullanıldığı cihaz 9 kademeli olarak çalıştırılmaktadır. 9 kademe de ayrı ayrı mmSS (milimetre su seviyesi) birimde vakum ölçümleri yapılmıştır. Tablo 3'de ölçüm yapılan değerler görülmektedir.

Tablo 3. Mevcut aparatta temizlik robotunun teknik değerleri

\begin{tabular}{ccccc}
\hline $\begin{array}{c}\text { Cihaz Çalışma } \\
\text { Kademesi }\end{array}$ & $\begin{array}{c}\text { Verilen } \\
\text { Voltaj (V) }\end{array}$ & $\begin{array}{c}\text { Güç } \\
\text { (W) }\end{array}$ & $\begin{array}{c}\text { Amper } \\
(\mathrm{A})\end{array}$ & $\begin{array}{c}\text { Vakum } \\
\text { (mmSS) }\end{array}$ \\
\hline 1 kademe & 106 & 144 & 2,412 & 110 \\
2 kademe & 119,2 & 201,4 & 2,752 & 250 \\
3 kademe & 134,4 & 285 & 2,912 & 315 \\
4 kademe & 151,1 & 391 & 3,415 & 485 \\
5 kademe & 168,6 & 516 & 3,754 & 610 \\
6 kademe & 186,5 & 671 & 4,289 & 785 \\
7 kademe & 205,6 & 857 & 4,854 & 860 \\
8 kademe & 218 & 978 & 4,985 & 1085 \\
9 kademe & 230 & 1136 & 5,265 & 1190 \\
\hline
\end{tabular}

\subsection{Mevcut Koltuk Aparatının Emiş Vakum Değeri}

Koltuk kanepe aparatının kılların çıkartılabilir olması için mevcut tasarımına uygun olacak şekilde bir tasarım yapılması gerekmektedir. Yapılacak olan bu iyileştirme çalışması maliyeti en düşük olması gerekmektedir. Bu amaçla koltuk kanepe aparatının gövde ve kırmızı parçası kullanılması düşünülmüştür. Ayrı bir parça tasarımı yapılarak gövdeye montaj yapılması hedeflenmiştir. Bu parça üzerine kılların montajlanması düşünülmüştür. $\mathrm{Bu}$ kriterlere bağlı olarak şekil 18'deki bir kavram tasarımı oluşturulmuştur.

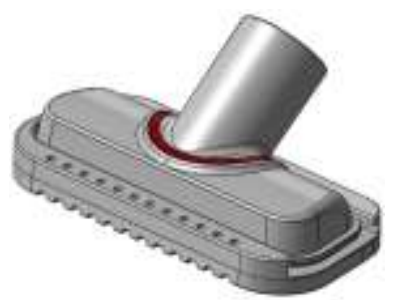

Şekil 18. Geliştirilen kavram tasarımı

Tasarımı geliştirilen tasarım incelendiğinden alttaki parça yandan takılıp çıkartılmaktadır. Koltuk kanepe parçasının ana gövdesinde mevcut bulunan eteklerindeki çıkıntılar kızaklamada kullanılarak montaj yapılması sağlanmıştır. Şekil 19'da parçanın de montaj hali görülmektedir. 


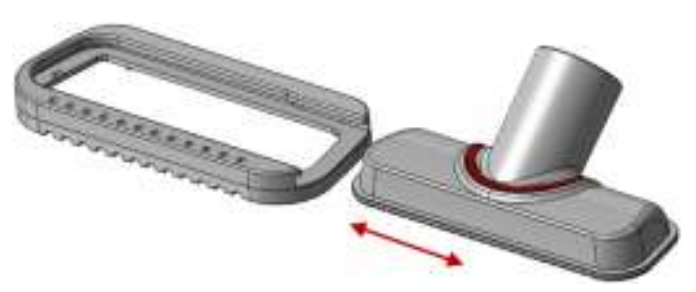

Şekil 19. Geliștirilen kavram tasarımın de montaj hali

Koltuk kanepe aparatı kullanım sırasında kızaktan çıkmaması için firça parçasında kitleme için çıkıntı yapılmıştır. Fırça parçasının montaj halde iken yandan vurularak çıkıntıyı atlatılarak firça parçası çıkartılması düşünülmüştür. Şekil 20'de kitleme durumu görülmektedir.

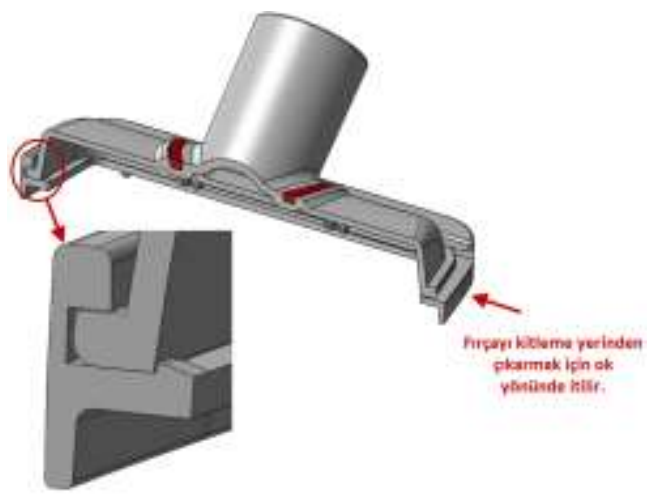

Şekil 20. Geliştirilen kavram tasarımın kitleme durumu

\subsection{Koltuk Kanepe Aparatının Prototip Üretimi Vakum Testi}

Koltuk kanepe aparatının firça tasarımı için geliştirilen tasarımının montaj kontrolü ve vakum testi için prototipi üretilmiştir. Prototip üretimim Stratsys firmasının FDM 360MC makinasında yapılmıştır. Şekil 21'de fırça parçasının üretilen prototipi görülmektedir.

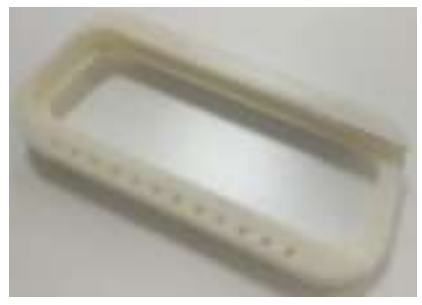

Şekil 21. Fırça parçası prototipi

Fırça parçası kılların montaj edilmesi için başka bir firmaya gönderilerek PA66 0,2mm kalınlıkta ve \%40 oranında at kılları montaj edilmiştir. Kılların montaj edilmiş hali şekil 22'de görülmektedir.

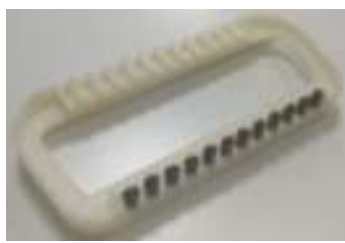

Şekil 22. Fırça parçasına kılların montaj hali

Şekil 23’te görüldüğü gibi yeni koltuk kanepe aparatının vakum değerinin ölçülmesi için ölçüm aparatı montajı yapılmıştır. 9 kademe de ayrı ayrı vakum ölçümleri yapılmıştır. Tablo 4'te yeni koltuk kanepe aparatında ölçüm yapılan değerler görülmektedir.

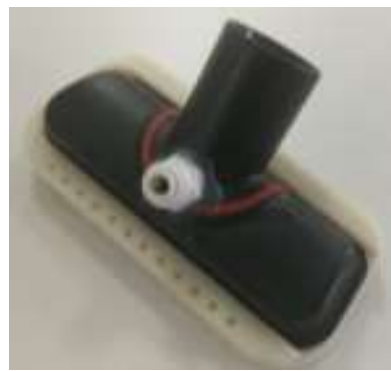

Şekil 23. Fırça parçasına kılların montaj hali

Tablo 4. Yeni koltuk kanepe aparatta temizlik robotunun teknik değerleri

\begin{tabular}{ccccc}
\hline $\begin{array}{c}\text { Cihaz Çalıșma } \\
\text { Kademesi }\end{array}$ & $\begin{array}{c}\text { Verilen } \\
\text { Voltaj (V) }\end{array}$ & $\begin{array}{c}\text { Güç } \\
(\mathrm{W})\end{array}$ & $\begin{array}{c}\text { Amper } \\
(\mathrm{A})\end{array}$ & $\begin{array}{c}\text { Vakum } \\
(\mathrm{mmSS})\end{array}$ \\
\hline 1 kademe & 106 & 146 & 2,432 & 115 \\
2 kademe & 119,2 & 200,5 & 2,745 & 245 \\
3 kademe & 134,4 & 291 & 2,956 & 335 \\
4 kademe & 151,1 & 405 & 3,430 & 495 \\
5 kademe & 168,6 & 529 & 3,805 & 640 \\
6 kademe & 186,5 & 685 & 4,295 & 800 \\
7 kademe & 205,6 & 878 & 4,889 & 890 \\
8 kademe & 218 & 996 & 5,012 & 1105 \\
9 kademe & 230 & 1175 & 5,294 & 1230 \\
\hline
\end{tabular}

\section{Dar Yüzeylerde Kullanılan Mevcut Aparat Geliştirilmesi}

Tasarımı geliștirilecek aparat ile ilgili olarak;
$\checkmark \quad$ Dar yüzeylerin kolay temizlenmesi
$\checkmark$ Hassas yüzeylerin kolay temizlenmesi
$\checkmark$ Emiş ağzının esnek olması
$\checkmark$ Ulaşılması zor alanların temizlenmesi

Mevcut ürün ile gönderilen aparat ile kenar köşeleri ve koltukların keskin köşelerin temizlenmesini sağlamaktadır. Șekil 25'te mevcut kullanılan kenar köșe aparatı görülmektedir.

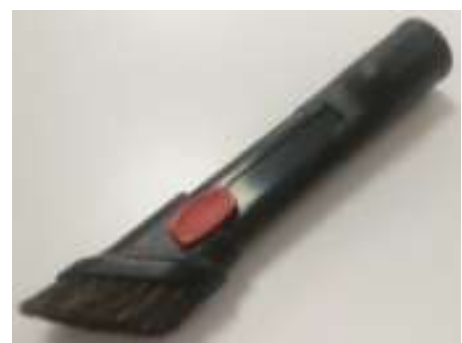


Şekil 25. Kenar köșe aparatı

$\mathrm{Bu}$ aparat fırçalı ve fırçasız olarak kullanılmaktadır. Aparat yanda bulunan kırmızı parça geriye doğru çekildiğinde kitleme yerinden kurtulmaktadır. Daha sonra firçalı parça geriye doğru çekilerek arka dip noktasında yuvaya oturmaktadır. Daha sonra kırmızı parça ileri itilerek firçalı parça sabitlenmiş olur. Bu sayede aparatı fırçasız olarak kullanılması sağlanır. Fırçalı kullanılmak istenildiğinde bu işlemler tersine uygulanılır. Şekil 26'da kenar köşe aparatının firçalı ve firçasız hali görülmektedir.

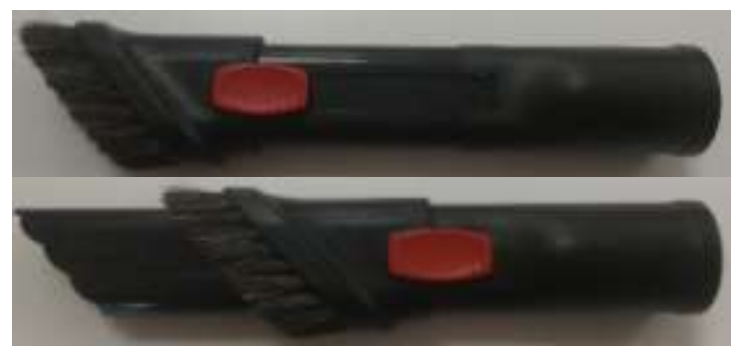

Şekil 26. Koltuk kanepe aparatı kıl grubu

Dar yüzeylerin temizlenmesinde kullanılan bu aparat tam olarak yüzeylerin temizlenmesini sağlamamaktadır. Aynı zamanda hassas yüzeylerin temizlenmesi sirasında yüzeylere zarar verebilmektedir. Şekil 27'de dar bir yüzeyin temizlendikten sonra bile kir olduğu görülmektedir. $\mathrm{Bu}$ sebeplerden ve müșterilerle yapılan anketlerde çıkan sonuçlarından dolayı bu aparatın geliştirilmesi gerekliliği ortaya çıkmıştır.

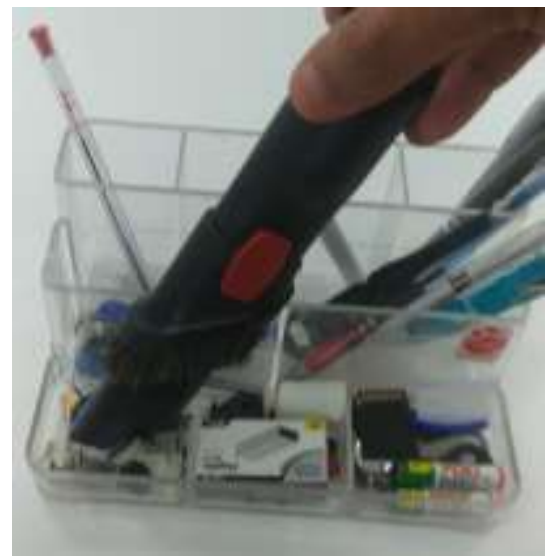

Șekil 27. Mevcut aparatın dar köșelerin temizlenmesi

\subsection{Dar Yüzeyler için Aparat Tasarımı Geliştirilmesi}

Mevcut kenar köşe aparatı firçalı ve firçasız olarak kullanılmak istenildiğinde yanda bulunan kaydırma parçası yukarı kaydırarak kitleme kaldırılmaktadır. Bu sayede fırçalı parça yanda bulunan kızaklar sayesinde yukarı kadar çıkartılabilmektedir. Şekil 28'de kitleme parçası ve kızaklar görülmektedir. Yukarı tekrar kitleme yapılarak mevcut parça firçalı ve fırçasız olarak kullanılır.

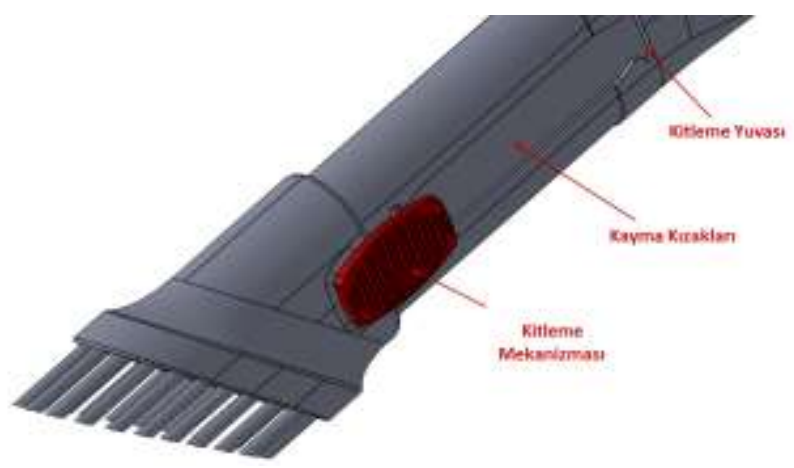

Şekil 28. Mevcut aparatın kitleme mekanizması ve kayma kızaklar

Kitleme mekanizmasının ileri veya geri hareket ederek şekil 29'da yan dilleri açarak yuvalarına girmesini sağlar bu sayede kitleme sağlamaktadır.

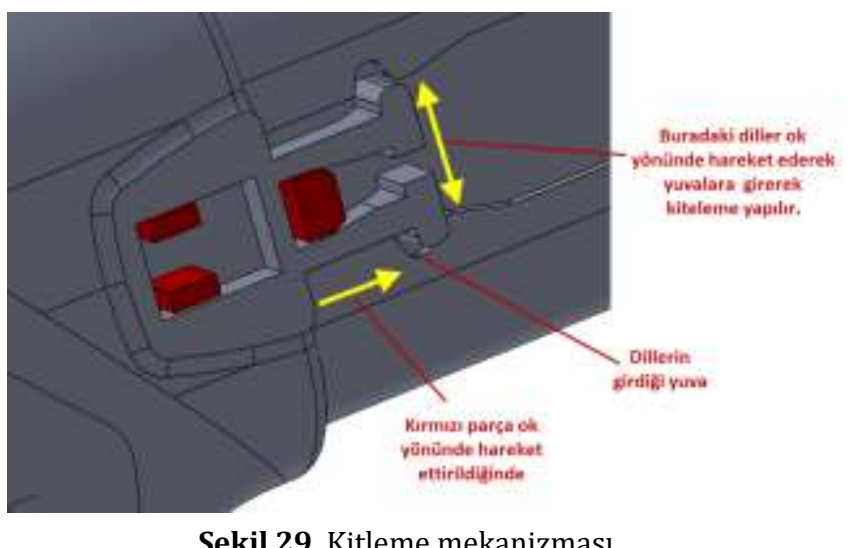

Tasarımı geliştirilecek parça hem firçalı, fırçasız, hassas ve dar yüzeylerin temizlenmesini sağlayacak şekilde ürün tasarımı yapılacaktır. Bu amaçla aparat ucunun yapılacak ișleme göre takılıp çıkartılabilen bir aparat tasarımı planlanmıștır. Şekil 30'de fırçalı ve firçasız olarak kullanılacak aparatın sökülüp takılabilen tasarımı görülmektedir. Bu aparat fırça kitleme sistemi mevcuttaki aynı sistemdir.
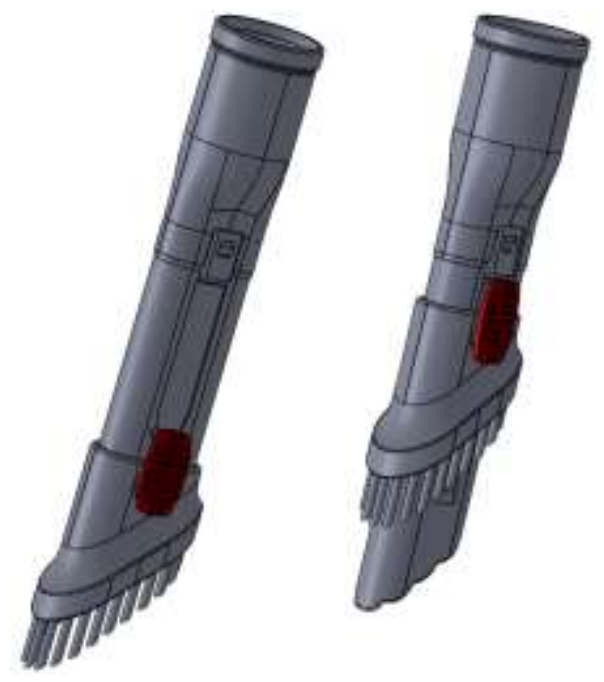

Şekil 30. Tasarımı geliştirilen fırçalı ve fırçasız durumu 


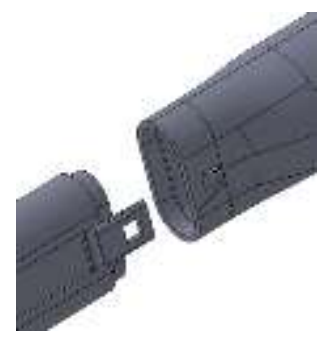

Șekil 31. Geliștirilen kavram tasarımın kitleme durumu

Geliştirilen ağız yapısının birbirine montaj edilme sistemi şekil 31'de görülmektedir. Dar ve hassas yüzeylerin temizlenmesi için emiş ağzının esnek olmalı ve dar alanlara girebilmesi için küçük yapıda olmalıdır. Daha önceki tecrübelerimizde cihazın vakum değeri yüksek olduğundan dolayı tek nokta ve dar alanda vakum oluşturulduğunda ıslık sesi oluşmaktadır. Ama bu küçük çaptaki vakum ağzından çok fazla olursa ıslık sesinin önüne geçilebilir. Bu amaçla çok noktada vakum oluşturmak ve bu vakum noktalarının esnek yapılarak hassas ve dar yerlerin temizlenmesi amaçlanmıștır. Şekil 32'de dar ve hassas yerlerin temizle aparatı görülmektedir.

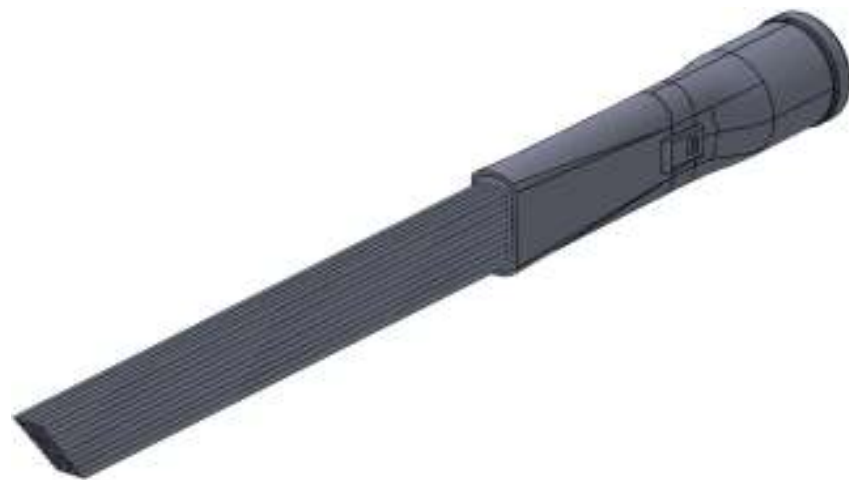

Şekil 32. Geliștirilen kavram tasarımın kitleme durumu

Dar ve hassas aparatının vakum ağzının iç çapları 1,5 mm diş çap olarak 2,8 mm olarak yapılmıştır. Bu borulardan aparatta 5 adet boy $200 \mathrm{~mm}$ olarak kullanılmıştır. Şekil 33'te vakum ağızları görülmektedir.

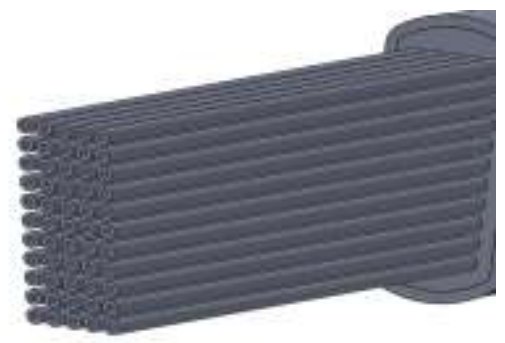

Şekil 33. Geliştirilen kavram tasarımın kitleme durumu

\subsection{Tasarımı Geliştirilen Aparatının Prototip Üretimi}

Mevcut aparat sisteminde firçalı ve firçasız olarak kullanıldığında dolayı bu kısmın prototipi yapılması hedeflenmemiștir. Dar ve hassas yüzeylerin temizlenmesi için geliştirilen kısmının prototip yapılmıştır. Bu kısım mevcut aparat üzerinde montajı yapılmıştır. Şekil 34'te prototip yapılan aparat görülmektedir.

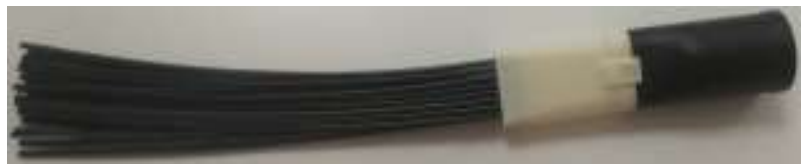

Şekil 34. Dar ve hassas yüzeylerin için geliștirilen tasarımının prototipi

Aparatın sökülüp çıkartılma kısmının prototipi şekil 35'de görülmektedir.

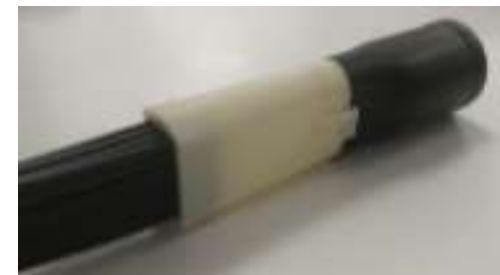

Şekil 35. Fırça parçasına kılların montaj hali

Şekil 36'da dar yüzeylerin temizlenmesi görülmektedir. Aparatın ucundaki esnek emiş ağızları sayesinde dar noktaların temizlenmesi daha kolay olacaktır. Bu sayede hem dar yüzeylerin kolay ve hızlı temizlenmesini sağlamakta aynı zamanda emiş ağızlarının esnek olmasından dolayı hassas yüzeylerin kolay temizlenmesini sağlayacaktır.

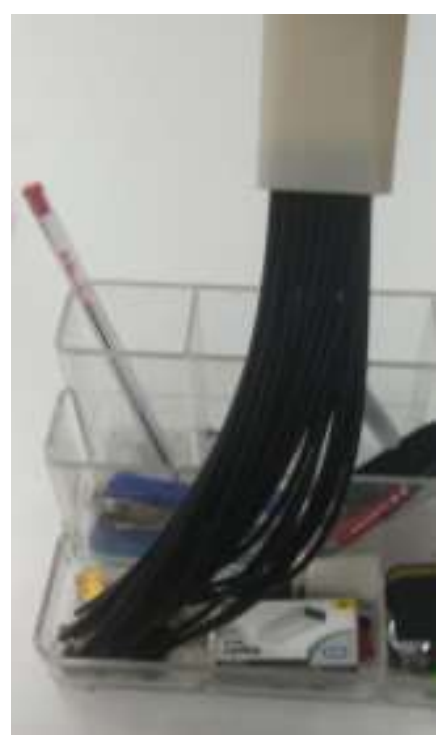

Şekil 36. Fırça parçasına kılların montaj hali

\section{Tartışma ve Sonuç}

$\mathrm{Bu}$ çalışmada cam, sert zemin ve parke marley yüzeylerin kimyasal sıvısıyla, koltuk kanepe yüzeylerin ve dar köşe ve kenarların temizlenmesi için aparatların geliştirilmesi hedeflenmiştir. Bu amaçla bütün farklı yüzeylerde kullanılan aparatlar 
incelenmiştir. Cam, sert zemin ve parke marley için aparat tasarımları geliştirilmiştir. Cam silme işlemi için aparatın bir yüzeyinde sünger ile temizlenmesi, aparat döndürülerek cam yüzeyde bulanan kirli sıvının emilmesini sağlayacak aparat tasarımı yapılmıştır. Aparat üzerindeki temizleme aparatın yanında bulunan çıkıntıya vurarak yuvadan çıkartılır. Yuvadan çıkan temizleme aracı aparat üzerinde bulunan kızaklardan çıkartılması sağlanır. Bu sayede temizlik yapılacak yüzeye göre temizleme aracı aparat üzerine montaj edilir. Yapılan tasarımlar tek bir aparat üzerine montaj edilerek kullanılabilmektedir. Bu sayede tek bir aparat üzerinde üç farklı yüzeyin temizlenmesini sağlanmaktadır. Üç farklı yüzey için temizlenmesi için kullanılacak ürün konseptine uygun aparat tasarımı geliştirilmesi yapılmıştır.

Koltuk kanepe aparat üzerinde firçalar vasıtasıyla koltuktaki tozları kaldırarak tozun temizlenmesini sağlamaktadır. Fakat son zamanlarda mobilya sektöründe koltuklarda farklı kumaşlar kullanılmakta, koltuk kanepe aparatındaki fırçalar bu kumaşlara zarar verebilmektedir. Bu amaçla koltuk kanepe aparatındaki kılların sökülüp takılması veya kullanılan kılların koltuk kumaşına zarar vermeyecek kıl kalınlığı kullanılması düşünülmüştür. Fakat kıl kalınlığı ince olduğu durumda daha önce farklı çalışmalarda kullanılmış ve kıllar kolay deforme olduğu görülmüștür. Bu nedenle ince kıl kalınlığı kullanması düşünülmemiştir. Kıl parçasının çıkartılabilir olması için kavram tasarımı yapılmıştır. Yapılan tasarımının prototipi üretilmiş, daha sonra aparatın vakum değerleri ölçülmüş ve mevcut ürünün vakum ölçümleri karşılaştırılmıştır. Sökülüp takılabilen fırça yapılı koltuk kanepe aparatı mevcut aparata göre $40 \mathrm{mmSS}$ vakum artığı tespit edilmiștir.

Kenar köşe aparatı dar köşelerin ve hassas yüzeylerin temizlenmesi zor olmaktadır. Bazen dar köşelerde tozlar kalmaktadır. Mevcut aparatının fonksiyonelliği olan firçalı ve firçasız şekilde kullanılması devam etmesi buna ek olarak dar ve hassas yüzeylerin temizlemesi sökülüp takılabilen aparat tasarımı yapılmıştır. Geliştirilen bu aparatta küçük çaplarda esnek emiş ağızlarından oluşmaktadır. Esnek emiş ağzının ölçüleri iç çapı Ø1,5 dış çapı Ø2,8 boyu $200 \mathrm{~mm}$ olarak belirlenmiştir. $\mathrm{Bu}$ emiş ağızlarından aparatta 55 adet kullanılmıştır. Bu şekilde tasarımı yapılmıştır, yapılan tasarımının prototipi üretilmiştir. Üretimi yapılan prototip ürün üzerinde montaj yapılmış ve dar yüzeylerde temizleme testleri yapılmıștır. Tasarımı geliștirilen aparatın dar ve hassas yüzeylerin temizlenmesi işlevini yerine getirdiği tespit edilmiştir.

\section{Kaynakça}

[1] Chen, K.-Z. 2000. Designing-in of High Value for Manufacturers in the New Millennium. Integrated Manufacturing Systems. 11(2000), 417-427.
[2] Büyüközkan, G., Derel_, T., Baykasoğlu, A. 2004. A Survey on the Methods and Tools of Concurrent New Product Development and Agile Manufacturing. Journal of Intelligent Manufacturing, 15(2000), 731-751.

[3] Bozdemir, M., Toktaş, I.2001. A systematic approach to conceptual design of mechanical systems, Pamukkale Univ Muh Bilim Derg. 7(2001),165-171.

[4] Bayazıt, N. 1994. Endüstri Ürünlerinde ve Mimarlıkta Tasarlama Metotlarına Giris. Literatür Yayınları, İstanbul.

[5] Rodriguez, K. and Al-Ashaab, A. 2005. Knowledge Web-based System Architecture for Collaborative Product Development. Computers in Industry. 56(2005), 125-140.

[6] Nevins, J., \& Whitney, D. 1989. Concurrent design of products and processes: A strategy for the next generation in manufacturing. McGraw-Hill Companies. New York.

[7] Schumpeter, J. 1942. Capitalism, Socialism and Democracy. Harper. New York.

[8] Bakerjian, R. 1992.Tool and Manufacturing Engineers Handbook. Society of Manufacturing Engineers. 1(1992), 30-58.

[9] Admin 2018. PVC Kapı ve pencere. http://www.yapitasarim.net/pvc-dograma/pvckapi-ve-pencere/ (Erişim Tarihi: 09.06.2018).

[10] İstanbul Çatı Yapı 2018. Fayans ve Kalebodur. https://istanbulcatiyapim.com/hizmetlerimiz/f ayans-ve-kalebodur/ (Erişim Tarihi: 09.06.2018)

[11] Admin 2018. Laminant Parke. https://www.intayapi.com.tr/sayfa/laminantparke/32 (Erişim Tarihi: 09.06.2018)

[12] Tchibo 2018. Mikrofiber Cam Temizleyici. https://www.tchibo.com.tr/mikrofibercam-temizleyici-p400023981.html (Erişim Tarihi: 09.06.2017)

[13] Tekzen 2018. Cam Silme Aparatı Uzun. https://www.tekzen.com.tr/teleskopikcekcekli-cam-silme-aparati-uzun-2372594 (Online Erişim: 09.06.2018)

[14] Tchibo 2018. Mavi Gri Teleskobik Cam Temizleyici. https://www.tchibo.com.tr/mavi-griteleskopik-cam-temizleyicip400096290.html (Erişim Tarihi: 09.06.2018)

[15] Karcher 2018. Buharlı Zemin Silme Aparatı Fircall. http://www.karchermarket- 
firatelektrik.com/hvz $\sim \mathrm{u} \sim$ karcher-de-4002-

buharli-zemin-silme-aparati-fircali (Erişim

Tarihi: 09.06.2018)

[16] Dyson 2018. Sert Zemin Aparatı. http://www.dysonmarket.com/dysondc52-sert-zemin-aparati (Erişim Tarihi: 09.06.2018)

[17] Nevreste 2018. Yer Nasıl Silinir. https://www.kadinlarkulubu.com/forum/threa ds/yer-nasil-silinir.863487/ (Erişim Tarihi: 09.06.2018)

[18] Admin 2018. Mop. http://www.photodictionary.com/phrase/1374/mop.html (Erişim Tarihi: 09.06.2018) 